\title{
Study of in vitro digestion of Tenebrio molitor flour for evaluation of its impact on the human gut microbiota
}

Article

Accepted Version

Creative Commons: Attribution-Noncommercial-No Derivative Works 4.0

de Carvalho, N. M., Walton, G. E., Poveda, C. G., Silva, S.N., Amorim, M., Madureira, A. R., Pintado, M. E., Gibson, G. R. and Jauregi, P. (2019) Study of in vitro digestion of Tenebrio molitor flour for evaluation of its impact on the human gut microbiota. Journal of Functional Foods, 59. pp. 101-109. ISSN 1756-4646 doi: https://doi.org/10.1016/j.jff.2019.05.024 Available at https://centaur.reading.ac.uk/84304/

It is advisable to refer to the publisher's version if you intend to cite from the work. See Guidance on citing.

To link to this article DOI: http://dx.doi.org/10.1016/j.jff.2019.05.024

Publisher: Elsevier

All outputs in CentAUR are protected by Intellectual Property Rights law, including copyright law. Copyright and IPR is retained by the creators or other copyright holders. Terms and conditions for use of this material are defined in the End User Agreement. 


\section{CentAUR}

Central Archive at the University of Reading

Reading's research outputs online 


\title{
Study of in vitro digestion of Tenebrio molitor flour for evaluation of its impact on the
} human gut microbiota

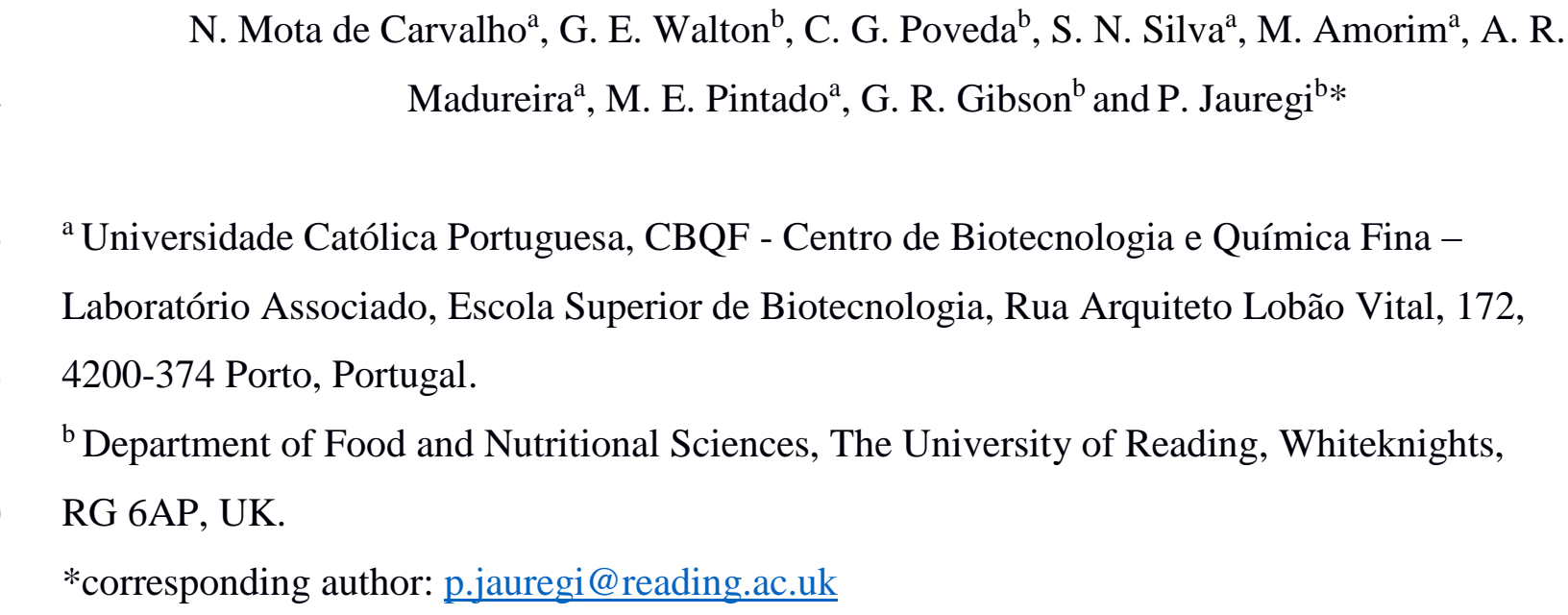

\begin{abstract}
Human diet has evolved to include not only nutritious foods but also health-promoting ones. Moreover, there is an increasing interest in replacing animal proteins as the main protein source. Insect based foods, e.g. Tenebrio molitor insect flour (TMIF), show potential as alternative protein sources for the human diet. This work aims to provide insights into the effect of TMIF upon the human gut microbiota and their metabolic end products by using an in vitro fecal model. Digested TMIF had a positive impact on gut microbiota, observed as an increase and/or upkeep of health promoting bacterial groups and by the production of SCFA (1.7 and 2.6 times higher acetate and propionate produced respectively than in the negative control at $48 \mathrm{~h}$ ) and BCFA. A path is opened to acknowledge TMIF as a possible healthy nutritional source for human consumption, although in vivo trials would be necessary to confirm this.
\end{abstract}

Keywords: in vitro digestion, anaerobic fecal fermentation model, insect flour, protein, gut microbiota, SCFA, BCFA

\section{Introduction}

Changes in consumer awareness of global food sustainability are leading to consideration of alternative protein sources. Emerging studies indicate that insects could be a good source of protein, fiber, fatty acids and amino acids (Chen et al., 2009; Kouřimská and Adámková, 2016; Mlcek et al., 2014; Premalatha et al., 2011). As such, research into the benefits of insect consumption to the consumer is required. Currently, one of the most commercially used insects 
is the mealworm, Tenebrio molitor, which can be used and consumed in a flour form (Van Huis et al., 2013).

Any non-digested portion of foods may provide an energy source for gut microbiota, residing mainly in the colon. This microbial community can be manipulated by diet and is known to have an impact on health. As such, an important perspective for the impact of food ingredients on the consumer can be obtained by investigating effects on host gut microbiota.

The microbiota includes pathogenic and non-pathogenic microorganisms, as well as eukaryotic and prokaryotic cells and viruses. This microbial consortium plays a key role in the breakdown of dietary fiber, vitamin synthesis, nutrient cycling and energy metabolism. It also acts as a physical barrier to prevent pathogens from colonizing the GIT through competitive exclusion (Charaslertrangsi, 2014). In an adult, the dominant phyla include Firmicutes, Bacteroidetes, Proteobacteria and Actinobacteria (Charaslertrangsi, 2014; Moon et al., 2016; Thursby and Juge, 2017). These bacteria are involved in immunological activity, energy consumption, intestinal permeability, intestinal motility, and even effects in the enteric nervous system and brain activities (Barczynska et al., 2016; Bull and Plummer, 2014; Carabotti et al., 2015; Conlon and Bird, 2014; Derrien and van Hylckama Vlieg, 2015; Fung et al., 2017; Kim et al., 2016; Mayer et al., 2015; Powell et al., 2017). Some of these actions are driven by the ability of the microbiota to produce short-chain fatty acids (SCFA) (Brüssow and Parkinson, 2014; Louis et al., 2014; Ríos-Covián et al., 2016). As such, SCFA are important end products of microbial fermentation and their production is highly dependent on substrates reaching the large intestine. The understanding of host-microbiota-food component interactions is of major significance, and for that, simulation models can help elucidate this complex relationship. In vitro digestion models are used to assess and simulate physicochemical and physiological events of the digestive tract, allowing studies of structural changes, bioavailability and digestibility of foods when they arrive at the colon (Hur et al., 2011; Lee et al., 2016). As such, in vitro fermentation models are useful tools to screen substances, from dietary ingredients to pathogens and to assess how they alter or are altered by gastrointestinal environments and microbial populations (Verhoeckx et al., 2015). In vitro fermentation allows cultivation of complex intestinal microbiota, in controlled conditions, to study metabolism (Moon et al., 2016).

The aim of this work was to evaluate the impact of an edible insect, Tenebrio molitor, on the human gut microbiota using an in-vitro digestion model. This is a very novel study, only one similar previous study has been reported by Stull et al. 2018, where the impact of edible cricket consumption on human gut microbiota was investigated in an in vivo study. Two samples of 
the insect in flour form (TMIF) were investigated, digested and undigested and anaerobic fecal fermentation models were used. The evaluation of the impact of the samples on the gut microbiota was carried out based on measurements of bacterial composition and short fatty acid production during a time course. This enabled assessment of the potential of TMIF to impact on the microbial community and its metabolites.

\section{Material and methods}

\subsection{Tenebrio molitor insect flour (TMIF)}

Tenebrio molitor insect flour (TMIF) was purchased from Insagri company, Málaga, Spain and kindly offered by Frulact company, Maia, Portugal. The composition and nutritional information of TMIF is shown in Table 1.

\subsection{TMIF sterilization}

To ensure TMIF was free of microorganisms, the sample was dried at $100^{\circ} \mathrm{C}$ for 24 hours.

\subsection{In vitro gastrointestinal digestion protocol}

The TMIF digestion used an in vitro method mimicking in vivo conditions as described by Mills et al. (2008) with slight modifications. $20 \mathrm{~g}$ of TMIF were ground and dissolved in $50 \mathrm{~mL}$ distilled water and the mixture put in a stomacher (Seward, Worthing, UK) for $5 \mathrm{~min}$. For the oral phase, $6.66 \mathrm{mg}$ of $\alpha$-amylase (A 4551, Sigma) in $2.08 \mathrm{~mL}$ of $0.001 \mathrm{M} \mathrm{CaCl}_{2}$ at $\mathrm{pH} 7.0$ was added and incubated at $37^{\circ} \mathrm{C}$ for $30 \mathrm{~min}$ on a shaker. After this, $6 \mathrm{M} \mathrm{HCl}$ was used to lower the $\mathrm{pH}$ to 2.0. For the gastric phase, $0.9 \mathrm{~g}$ of pepsin (P 7000, Sigma) was dissolved in $8.33 \mathrm{~mL}$ of $0.1 \mathrm{M} \mathrm{HCl}$ in a volumetric flask and this pepsin solution was added to the samples and incubated at $37^{\circ} \mathrm{C}$ for $2 \mathrm{~h}$ on a shaker. For the small intestinal phase, a pancreatin and bile solution was prepared. For that, $186.67 \mathrm{mg}$ of pancreatin (P 8096, Sigma) and $1.17 \mathrm{~g}$ of bile (B 8631, Sigma) were dissolved in $41.67 \mathrm{~mL}$ of $0.5 \mathrm{M} \mathrm{NaHCO}_{3}$, and $\mathrm{pH}$ was adjusted to 7.0 with either $6 \mathrm{M}$ of $\mathrm{HCl}$ or $\mathrm{NaOH}$ and incubated at $37^{\circ} \mathrm{C}$ for $3 \mathrm{~h}$ on a shaker. The simulated digestion process of the TMIF also included a dialysis step to simulate the absorption in small intestine, in order to analyze the different behavior of bacteria present in the gut microbiota (Alegría et al., 2015; Verhoeckx et al., 2015). All samples were transferred to 100-500 Da molecular weight cut-off regenerated cellulose dialysis tubing (Spectra/Por ${ }^{\circledR}$ 6, Spectrum Europe, Netherlands) and a dialysis was performed against $1 \mathrm{M} \mathrm{NaCl}$ at $5{ }^{\circ} \mathrm{C}$ to remove low molecular mass digestion products. After $15 \mathrm{~h}$, the dialysis fluid was changed and performed for two additional hours. Afterwards, all samples were transferred to a freeze dryer (Armfield SB4 model, Ringwood, 
UK) in order to obtain a powder (digested TMIF) to be used for in vitro fecal fermentations. All chemicals were purchased from Sigma (St. Louis, USA).

\subsection{Gut microbiota simulation: Fecal fermentations}

\subsubsection{Fecal microbiota}

Fecal samples were obtained fresh at the Department of Food and Nutritional Sciences, Reading from five healthy adult volunteers. The volunteers had normal omnivorous diets and had not ingested any antibiotics or other medicines known to affect the microbiota for at least 6 months prior to the study. Volunteers were 2 males and 3 females aged 22-37 years and were not regular consumers of prebiotics or probiotics. Samples were collected into clean containers and immediately placed in an anaerobic cabinet (nitrogen $80 \%$, carbon dioxide 10\%, hydrogen 10\%) (Don Whitley, UK) and used within $1 \mathrm{~h}$ of collection. A $10 \%$ (w/w) dilution in $0.1 \mathrm{M}$ phosphate-buffered saline pH 7.4 (PBS) solution was prepared and homogenized using a stomacher (Serward, Worthing, UK) for $2 \mathrm{~min}$ at 460 paddle-beats per min. This produced a fecal slurry.

\subsubsection{Fecal batch-culture fermentation conditions}

Five independent fermentations were carried out using a sample from each donor. Sterile stirred batch culture fermentation vessels of $300 \mathrm{~mL}$ were set up and aseptically filled with $135 \mathrm{~mL}$ sterile basal nutrient medium (peptone water $2 \mathrm{~g} / \mathrm{L}$, yeast extract $2 \mathrm{~g} / \mathrm{L}, \mathrm{NaCl} 0.1 \mathrm{~g} / \mathrm{L}, \mathrm{K}_{2} \mathrm{HPO}_{4}$ $0.04 \mathrm{~g} / \mathrm{L}, \mathrm{KH}_{2} \mathrm{PO}_{4} 0.04 \mathrm{~g} / \mathrm{L}, \mathrm{MgSO}_{4} .7 \mathrm{H}_{2} \mathrm{O} 0.01 \mathrm{~g} / \mathrm{L}, \mathrm{CaCl}_{2} .6 \mathrm{H}_{2} \mathrm{O} 0.01 \mathrm{~g} / \mathrm{L}, \mathrm{NaHCO}_{3} 2 \mathrm{~g} / \mathrm{L}$, Tween $802 \mathrm{~mL} / \mathrm{L}$, hemin $0.05 \mathrm{~g} / \mathrm{L}$, vitamin K $10 \mu \mathrm{L} / \mathrm{L}$, L-cysteine $\mathrm{HCl} 0.5 \mathrm{~g} / \mathrm{L}$, bile salts 0.5 $\mathrm{g} / \mathrm{L}$ and resazurin $4 \mathrm{mg} / \mathrm{L}$ ) and gassed overnight with $\mathrm{O}_{2}$-free $\mathrm{N}_{2}$ with constant agitation. The temperature was kept at $37^{\circ} \mathrm{C}$. Four stirred $\mathrm{pH}$-controlled batch fermenters were run in parallel: (1) $1 \%(w / v)$ digested TMIF was aseptically added; (2) $1 \%(w / v)$ undigested TMIF was aseptically added; (3) a positive control with 1\% (w/v) FOS (a known prebiotic) from chicory root, purity: > 95\%, degree of polymerization ranging from 2 to 8 (Megazyme, Bray, Ireland) and (4) a negative control which had no source of carbon added. Each vessel, with $135 \mathrm{~mL}$ of sterile basal nutrient medium was inoculated with $15 \mathrm{~mL}$ of fresh fecal slurry. A FerMac 260 pH Controller (Electrolab Biotech Ltd., Tewkesbury, Gloucestershire, UK) was used, at $37^{\circ} \mathrm{C}$, to maintain pH for each vessel between 6.7 and 6.9 (Sánchez-Patán et al., 2012).The batch cultures were conducted under anaerobic conditions at $37{ }^{\circ} \mathrm{C}$ during $48 \mathrm{~h}$, in which $5 \mathrm{~mL}$ samples were collected from each vessel at $0,4,8,24$ and $48 \mathrm{~h}$ for bacterial enumeration by fluorescence in situ hybridization (FISH), analysis of SCFA, BCFA and lactate by gas 
chromatography (GC) and quantification of ammonia with 53659-FluoroSelectTM Ammonia Kit (Sigma-Aldrich, Gillingham, Dorset, UK). All media and chemicals were purchased from Oxoid (Basingstoke, UK) and Sigma (St. Louis, USA).

\subsection{Bacterial enumeration by FISH-FCM}

Samples were analyzed by fluorescence in situ hybridization combined with flow cytometry (FISH-FCM) in order to determine differences in bacterial composition in the batch cultures. The FISH-FCM was performed according to the protocol used by Grimaldi et al. (2017) with slight modifications on volumes used on the permeabilization steps where, in this case, $150 \mu \mathrm{L}$ of fixed batch culture samples were added to $500 \mu \mathrm{L} 1 \mathrm{x}$ PBS.

Table 2 shows the probes used (Eurofins Genomics, Ebersberg, Germany) in this protocol (Daims et al., 1999; Devereux et al., 1992; Franks et al., 1998; Harmsen et al., 1999; Harmsen et al., 2000; Hold et al., 2003; Langendijk et al., 1995; Manz et al., 1996; Walker et al., 2005; Wallner et al., 1993). Samples were stored at $4{ }^{\circ} \mathrm{C}$ until flow cytometry (FCM) analysis by a BD Accuri ${ }^{\text {TM }}$ C6 Cytometer (BD, Winnersh, Wokingham, UK). Numbers of specific and total bacteria were determined considering the dilution factor, calculated from different volumes used in the different steps of the preparation of the samples, and events/ $\mu \mathrm{L}$ obtained from Non Eub338 and Eub338 I-II-III probes analyzed by FCM.

\subsection{Evaluation of organic acids production by GC}

GC analysis was performed to evaluate the production of organic acids by the gut microbiota, From fecal batch cultures, $1 \mathrm{~mL}$ of sample of each vessel was transferred to a flat-bottomed glass tube and $50 \mu \mathrm{L}$ of 2-ethylbutyric solution added to each tube. In the fume hood, $500 \mu \mathrm{L}$ of concentrated $\mathrm{HCl}$ and $3 \mathrm{~mL}$ diethyl ether was added and vortexed. The tubes were centrifuged at $720 \mathrm{xg}$ for 10 minutes at room temperature $\left(18^{\circ} \mathrm{C}\right)$. The tubes went back again into the fume hood, where $400 \mu \mathrm{L}$ upper layer of the tubes were transferred into GC-vials and $50 \mu \mathrm{L}$ of Ntert-butyldimethylsilyl-N-methyltrifluoroacetamide (MTBSTFA) added to each GC-vial. The vials were left at room temperature for at least 72 hours before conducting GC analysis. Production of the SCFA, BCFA (branched chain fatty acids) and lactate was determined by an Agilent/HP 6890 Gas Chromatograph (Hewlett Packard, UK) using an HP-5MS $30 \mathrm{~m} \times 0.25 \mathrm{~mm}$ column with a $0.25 \mu \mathrm{m}$ coating (Crosslinked (5\%-Phenyl)-methylpolysiloxane) (Hewlett Packard, UK). Temperatures of injector and detector were $275^{\circ} \mathrm{C}$, with the column programmed from $63{ }^{\circ} \mathrm{C}$ for initial time ( 0 minutes) to $190{ }^{\circ} \mathrm{C}$ at $15^{\circ} \mathrm{C} \mathrm{min}{ }^{-1}$ and held at $190{ }^{\circ} \mathrm{C}$ for $3 \mathrm{~min}$. Helium was the carrier gas (flow rate $1.7 \mathrm{~mL} / \mathrm{min}$; head pressure $133 \mathrm{KPa}$ ). A split ratio of 
100:1 was used. Peaks were integrated using Agilent ChemStation software (Agilent

171 Technologies, Oxford, UK) and organic acids content quantified by multiple-point internal standard method $(12.5,25,50,75$ and $100 \mathrm{mM})$. Peak identity and internal response factors were determined using $0.1 \mathrm{mM}$ calibration cocktail including acetate, propionate, isobutyrate, butyrate, isovalerate, valerate and lactate.

\subsection{Evaluation of ammonia production}

Quantification of ammonia present in the studied samples was performed with 53659FluoroSelect ${ }^{\mathrm{TM}}$ Ammonia Kit (Sigma-Aldrich, Gillingham, Dorset, UK) following the protocol that was provided by the kit. Briefly $o$-phthalaldehyde reagent was reacted with an amino acid solution and sulfite (reagent $\mathrm{A}$ ) resulting in a color change in the presence of ammonia. As such a calibration curve of ammonia concentration was constructed alongside samples by recording fluorescence intensity at a wavelength of 360/460nm using a Tecan plate reader (Tecan Genios, Switzerland).

\section{Results and Discussion}

The impact of TMIF on the gut microbiota was assessed based on determination of bacterial composition by a molecular quantitative technique, FISH-FCM. Moreover, metabolic activity was determined based on the production of SCFA, BCFA and lactate; the amount of ammonia produced during fermentation was also determined. 
Digested and undigested TMIF results for total bacteria were not significantly different and were very similar to those of the negative control. The digested TMIF sample should be richer in end-products (e.g. small peptides, amino acids) than the undigested TMIF upon simulated digestion. However, both products were subjected to a final dialysis step which should remove all small molecular products such as, free fatty acids, small peptides and amino acids. This would explain why no differences were observed in total bacteria between the two TMIF samples.

Positive control (FOS) as expected, exhibited the most significant bacterial growth throughout the study period. In general, at all conditions, the concentration of different bacteria present in the fermentation vessels increased during the first $8 \mathrm{~h}$ of incubation.

Results of bacterial composition are shown in Fig 1. Bifidobacterium spp. growth showed similar outcomes over incubation time for the digested and undigested TMIF. Bifidobacterium spp. on the positive control showed significant growth increase compared to the other conditions. Results obtained for Lactobacillus spp. showed a similar growth profile to those obtained for Bifidobacterium spp. Overall, better growth of Bifidobacterium spp. and Lactobacillus spp. was observed for samples with carbohydrates as substrate than with the two samples of TMIF which are predominantly protein.

Growth of Bacteroidaceae and Prevotellaceae with TMIF samples (digested and undigested) were similar to the positive control. This may indicate, in this case, a positive impact of TMIF, as it partially matches the effect of FOS, in terms of bacteria upkeep, thus indicating that TMIF can be used as substrate by these bacteria. Bacteroides spp. possess strong peptidase activity and are associated with isovalerate and isobutyrate production (Scott et al., 2013; Zhao et al., 2016). This means that Bacteroidaceae and Prevotellaceae, depending on the type of substrate, can utilize effectively both its saccharolytic and proteolytic pathways for growth.

The growth of Atopobium cluster, has been reported to be increased by disaccharides, polysaccharides and long-chain inulin (Vinke et al., 2017). This seems to agree with results obtained with the positive control, where Atopobium cluster showed a significant increase at 8 $\mathrm{h}$ and maintained these levels up to $48 \mathrm{~h}$. In the presence of both forms of TMIF at $8 \mathrm{~h}$, small and similar growth was observed. In the same samples, at 24 and $48 \mathrm{~h}$, the results differed - the sample with the undigested form maintained the Atopobium cluster concentration level over such periods, while, in the digested form sample, a slight increase was observed, later followed by a decrease at $48 \mathrm{~h}$. Atopobium cluster is relatively unresearched, and very few studies demonstrate a correlation between its presence and human health. Nevertheless, it has been 
reported that the presence of Atopobium correlated with beneficial effects in terms of cardiometabolic health (Vinke et al., 2017).

Regarding the Clostridium coccoides / Eubacterium rectale group at $8 \mathrm{~h}$, the sample with digested TMIF showed a significant decrease in cell numbers. In the case of undigested TMIF, positive and negative control no significant deviation was seen gin their growth profile (Fig 1). The Clostridium coccoides / Eubacterium rectale, is a group of anaerobic bacteria, well-known for butyrate production, as are Roseburia and F. prausnitzii, in the gut microbiota (Lopetuso et al., 2013). The Clostridium histolyticum group, is a clostridial group that possesses some pathogenic species such as Clostridium perfringens and Clostridium tetani. This group showed no significant deviations between samples at specific study times, except for positive control at 24 and $48 \mathrm{~h}$. Clostridia are proteolytic bacteria and some clostridia possess saccharolytic activity, preferably fermenting amino acids (Rowland et al., 2017; Scott et al., 2013).

The Roseburia genera is also abundant in the intestinal microbiota, and it can produce both propionate and butyrate (Ríos-Covián et al., 2016). Roseburia spp. can grow in presence of carbohydrate, and some Roseburia spp. have FOS degradation genes or an inducible fructan utilization operon (Scott et al., 2013; Scott et al., 2015). In this work, Roseburia showed slight growth in the presence of FOS at 8 and $24 \mathrm{~h}$ (Fig 1). At $48 \mathrm{~h}$, a major decrease in Roseburia was observed, in the positive control, which may be explained by a decrease in FOS availability as it was being utilized during fermentation. In the presence of TMIF, a decrease was observed but the undigested form always maintained a higher concentration compared to the digested form.

The Clostridium cluster IX belongs to the group of bacteria that mainly produce propionate in gut microbiota and use amino acids as main source of energy (Bernalier-Donadille, 2010; Tottey et al., 2017; Van den Abbeele et al., 2010). At 8 h, growth of this cluster was observed in the presence of TMIF, mostly in the undigested form sample. At $24 \mathrm{~h}$ the bacteria growth profile on FOS and TMIF samples were similar and at $48 \mathrm{~h}$, a decrease was observed in all samples however, in the samples with undigested TMIF such a decrease was lower; nevertheless, these differences were not significant. In samples with TMIF, growth was expected, due to the presence of amino acids. As for the samples with FOS, growth was observed up to $24 \mathrm{~h}$, which must be related with cross-feeding process, as these bacteria use lactate (previously produced by other bacteria) as substrate to produce propionate (BernalierDonadille, 2010; Louis and Flint, 2017), which can be related to the lactate disappearance after $8 \mathrm{~h}$ in the Fig 1.The cross feeding process may also explain the Clostridium histolyticum group growth in presence of FOS, up to the same study time $(24 \mathrm{~h})$. 
Faecalibacterium prausnitzii, a strictly anaerobic bacterium, is one of the most abundant species present in healthy human microbiota. It is one of the main butyrate producers (Conlon and Bird, 2014; Scott et al., 2015). In the presence of digested TMIF, bacteria growth showed a decrease over time. For the positive and negative control was also observed a decreasing growth profile over time. The sample with undigested TMIF, was the only one that showed, at $8 \mathrm{~h}$, slight growth of these bacteria.

Desulfovibrionales and Desulfuromonales are only found in approximately fifty percent of humans (Rey et al., 2013). Predominant sulphate-reducing bacteria (SRB) in human colon are members of the genus Desulfovibrio. They can use hydrogen or organic compounds like lactate and formate to reduce sulphate to generate hydrogen sulphide $\left(\mathrm{H}_{2} \mathrm{~S}\right)$, which has a toxic nature, that can have pathological consequences for the host (Conlon and Bird, 2014; Rowland et al., 2017). Several studies identified SRB in the fecal microbiota of healthy adults and, despite being positively correlated with inflammation, the presence of $\mathrm{H}_{2} \mathrm{~S}$, has been attributed both to pro and anti-inflammatory signaling (Levine et al., 1998; Pitcher et al., 2000; Rey et al., 2013; Wallace et al., 2009). Lactate is also a favored co-substrate for these bacteria, forming acetate and sulphides. Desulfovibrio was reported to decrease in the presence of inulin, and studies showed that its lowered abundance can benefit health (Vinke et al., 2017). For this study, this group of bacteria was found in lower concentrations in the fecal samples of the donors, compared to other quantified groups. At $8 \mathrm{~h}$, for all samples, there was a small increase of Desulfovibrionales and Desulfuromonales with no significant differences between the samples. After $8 \mathrm{~h} \mathrm{(24}$ and $48 \mathrm{~h})$ a decline over time was observed. The small increase of these bacteria at $8 \mathrm{~h}$ may be correlated with the availability of lactate at that time (Fig 1).

In this study, it was possible to see the effect of undigested and digested TMIF through modulation of gut bacterial populations. The most marked results were found on the growth of Bacteroidaceae and Prevotellaceae, which are bacteria related to proteolytic and saccharolytic activity conferring benefits to the host through their activity (e.g. propionate production). Such results make sense since TMIF is predominantly protein. It is important to highlight the fact that digested TMIF did not promote the growth of butyrate producers during the fermentation, such as Clostridium coccoides / Eubacterium rectale group, Roseburia subcluster and Faecalibacterium prausnitzii, while undigested TMIF promoted growth or maintained these bacteria. This study indicates an influence of TMIF on bacterial populations of the human gut microbiota however, in vivo studies must be carried out in order to evaluate the impact of such bacterial group variations on humans. 
Acetate, propionate and butyrate are the most abundant SCFA existing in the colon, normally present in molar ratios ranging from 3:1:1 to 10:2:1 (Ríos-Covián et al., 2016; Rowland et al., 2017; Scott et al., 2013; Tan et al., 2014). In this study SCFA and BCFA were found (Fig 2 and 3).

As a general overview, acetate, propionate and butyrate concentrations were significantly higher overtime for digested and undigested TMIF in comparison to the negative control (Fig 2). In all cases, the positive control sample had significantly higher concentrations than the other samples.

Butyrate is an important SCFA for human health. It provides an energy source for human colonocytes, possesses potential anti-cancer activities by inducing apoptosis of colon cancer cells and regulating gene expression, it nourishes intestinal cells and induces mucin production allowing changes in bacterial adhesion and improving tight-junction integrity (Barczynska et al., 2016; Ríos-Covián et al., 2016; Rowland et al., 2017). TMIF samples showed increased production of this SCFA (with higher production for the undigested form). Propionate acts as an energy source for epithelial cells, has a positive effect on the growth of hepatocytes, and also plays a role in gluconeogenesis in the liver (Barczynska et al., 2016; Ríos-Covián et al., 2016; Rowland et al., 2017). Propionate is also correlated with the promotion of satiety and with the reduction of cholesterol (Louis and Flint, 2017). This study showed an increased production of this SCFA over time and higher production in TMIF samples than in negative control (Fig 2). Acetate, which can be produced by bifidobacteria is an essential co-factor/metabolite for the growth of other bacteria, and even to inhibit enteropathogens (Ríos-Covián et al., 2016; Rowland et al., 2017). Acetate was also found to reduce the appetite through the interaction with the central nervous system (Ríos-Covián et al., 2016). Acetate is used by the human body in cholesterol metabolism and lipogenesis (Rowland et al., 2017). The present study supports the findings that acetate is one of the most abundant SCFA, as it shows high production values particularly after 8 hours (Fig 2). This was also observed in the TMIF samples where acetate concentration was higher than in the negative control sample, indicating that TMIF fermentation resulted in production of this acid. Although for the undigested and digested TMIF the acetate and propionate production were almost the same, the undigested sample had higher production of butyrate compared to the digested form. Overall these results are promising for the application of TMIF as a substitute of animal derived proteins in foods since acetate and propionate are both associated with the promotion of satiety. 
Lactate is also produced by bacteria, such as bifidobacteria and proteobacteria, despite not being a SCFA. In addition, lactate can also be used by butyrate and propionate producing bacteria, avoiding accumulation and metabolic acidosis (Flint et al., 2015; Ríos-Covián et al., 2016). Lactate production was higher in fermentation of FOS than in the other samples. No significant difference was found between the negative control and TMIF samples. An interesting result was observed in all samples as there was no lactate after $8 \mathrm{~h}$ (at 24 and $48 \mathrm{~h}$ ). This is an expected result since, under normal physiological conditions, lactate does not accumulate in the colon because of its conversion into different organic acids through metabolic cross-feeding (Flint et al., 2015; Ríos-Covián et al., 2016; Rowland et al., 2017).

TMIF samples produced higher concentration of BCFA than both the negative and positive controls particularly after 24 hours (Fig 3). The undigested TMIF sample was the one with the highest concentration of valerate, isobutyrate and isovalerate, especially at 24 and $48 \mathrm{~h}$. Concentrations of these acids at $0 \mathrm{~h}$ and $4 \mathrm{~h}$ are null or very low for most trials, and significant levels appear mainly after $8 \mathrm{~h}$. Moreover, digested TMIF was the only sample to show no valerate production. Little is known of the potential health benefit of valeric acids, how they are produced in the gut microbiota and what type of bacteria are these acids related to (RíosCovián et al., 2016).

These results showed a major impact of TMIF in the undigested form, especially over $8 \mathrm{~h}$, on the production of the valerate, isobutyrate and isovalerate, which are normally present at low concentration in the human colon while acetate, propionate and butyrate are the most abundant (90-95\%) (Huda-Faujan et al., 2010; Ríos-Covián et al., 2016). Isobutyrate and isovalerate are primarily produced from the protein degradation particularly, from branched amino acids fermentation and an increase in production of these acids maybe observed when the presence of carbohydrate is limited (Huda-Faujan et al., 2010). Fecal concentrations of BCFA are markers for bacterial protein fermentation, and not actual indicators of colonic health (Bernalier-Donadille, 2010; Scott et al., 2013; Verbeke et al., 2015).

In summary, TMIF, in undigested or digested form, showed a positive impact on the production of SCFA and BCFA. The production of these by the gut microbiota may contribute to the host's well-being.

\subsection{Analysis of the impact on ammonia production}

Considering the high protein level of TMIF, a small increase of ammonia may be expected with the fermentation of this substrate, as ammonia forms from the deamination of amino acids 
369 (Conlon and Bird, 2014; Davila et al., 2013; Ríos-Covián et al., 2016; Rowland et al., 2017;

370 Scott et al., 2013). The presence of ammonia is an indicator of protein presence and degradation.

371 Ammonia levels increased overtime in the presence of digested and undigested TMIF, in a

372 similar concentration and pattern, except at $8 \mathrm{~h}$ (Fig 4). Bacteria degrade the protein present in

373 the samples, thus becoming an indicator of protein degradation, occurring along the

374 fermentation time.

375 Fecal ammonia concentration in humans varies between $12 \mathrm{mM}$ to $30 \mathrm{mM}$ and increase with

376 high intakes of protein (Scott et al., 2013). Higher levels can be considered negative for colonocytes, however, ammonia concentration levels obtained in this study seem to be within “safe levels" (up to $70 \mathrm{mM}$ ) (Leschelle et al., 2002; Tsujii et al. 1992).

\section{Conclusions}

381

382

383

384

385

386

387

388

389

390

391

392

393

394

395

396

397

398

399

400

According to the gut microbiota fecal in vitro model, TMIF had a positive impact as it promoted the growth of Bacteroidaceae and Prevotellaceae but not of Clostridium histolyticum group or Desulfovibrionales and Desulfuromonales. Also, TMIF showed a positive impact on the production of SCFA especially acetate and propionate and on the production of BCFA. The ammonia production in the TMIF samples was within concentration levels that are considered to have no cytotoxic effects. Therefore, TMIF shows potential as a protein source for human consumption due to its nutritional content and SCFA generating properties. Moreover, TMIF resulted in an increase in the production of acetate and propionate, these compounds have been associated with promotion of satiety (Louis and Flint, 2017; Ríos-Covián et al., 2016).This also opens the possibility for a protein enriched product without animal derived proteins and possibly additional functionalities. Human trials will be required to prove the additional functionalities.

\section{Acknowledgments}

The authors would like to thank Frances Jackson and Holly Wang for their assistance in the running of the in vitro model.

Funding: This work was supported by Fundação para a Ciência e Tecnologia, Lisboa, Portugal [UID/Multi/50016/2013].

\section{Conflict of interest}


401

402

403

404

405

406

407

408

409

410

411

412

413

414

415

416

417

418

419

420

421

422

423

424

425

426

427

428

429

430

431

432

433

The authors have no financial or other type of relationship with insect industry that would present a conflict of interest.

\section{References}

1. Alegría, A., Garcia-Llatas, G., Cilla, A., 2015. Static digestion models: General introduction. In: Verhoeckx, K. et al. (Eds.), The Impact of Food Bioactives on Health. Springer, Cham, pp. 3-12.

2. Barczynska, R., Kapusniak, J., Litwin, M., Slizewska, K., Szalecki, M., 2016. Dextrins from maize starch as substances activating the growth of bacteroidetes and actinobacteria simultaneously inhibiting the growth of firmicutes, responsible for the occurrence of obesity. Plant Foods for Human Nutrition 71, 190-196. https://doi: 10.1007/s11130-0160542-9.

3. Bernalier-Donadille, A., 2010. Fermentative metabolism by the human gut microbiota. Gastroenterologie clinique et biologique 34, S16-S22. https://doi: 10.1016/S03998320(10)70016-6.

4. Brüssow, H., Parkinson, S.J., 2014. You are what you eat. Nature biotechnology 32, 243245. https://doi: 10.1038/nbt.2845.

5. Bull, M.J., Plummer, N.T., 2014. Part 1: The human gut microbiome in health and disease. Integrative medicine: a clinician's journal 13, 17-22. PMID: 26770121.

6. Carabotti, M., Scirocco, A., Maselli, M.A., Severi, C., 2015. The gut-brain axis: interactions between enteric microbiota, central and enteric nervous systems. Annals of gastroenterology: quarterly publication of the hellenic society of gastroenterology 28, 203209. PMID: 25830558.

7. Charaslertrangsi, T. 2014. Developing the multi-stage gut Simulator system to study gut microbiota. [Ph.D. Dissertation]. University of Guelph, Canada. pp. 326.

8. Chen, X., Feng, Y., Chen, Z., 2009. Common edible insects and their utilization in China. Entomological research 39, 299-303. https://doi: 10.1111/j.1748-5967.2009.00237.x.

9. Conlon, M.A., Bird, A.R., 2014. The impact of diet and lifestyle on gut microbiota and human health. Nutrients 7, 17-44. https://doi:10.3390/nu7010017.

10. Daims, H., Brühl, A., Amann, R., Schleifer, K.-H., Wagner, M., 1999. The domain-specific probe EUB338 is insufficient for the detection of all Bacteria: development and evaluation of a more comprehensive probe set. Systematic and applied microbiology 22, 434-444. https:// 10.1016/S0723-2020(99)80053-8. 
11. Davila, A.-M., Blachier, F., Gotteland, M., Andriamihaja, M., Benetti, P.-H., Sanz, Y., Tomé, D., 2013. Re-print of "Intestinal luminal nitrogen metabolism: Role of the gut microbiota and consequences for the host". Pharmacological research 69, 114-126. https:// doi: 10.1016/j.phrs.2013.01.003.

12. Derrien, M., van Hylckama Vlieg, J.E., 2015. Fate, activity, and impact of ingested bacteria within the human gut microbiota. Trends in microbiology 23, 354-366. https://doi: 10.1016/j.tim.2015.03.002.

13. Devereux, R., Kane, M.D., Winfrey, J., Stahl, D.A., 1992. Genus-and group-specific hybridization probes for determinative and environmental studies of sulfate-reducing bacteria. Systematic and applied microbiology 15, 601-609. https://doi: 10.1016/S07232020(11)80122-0.

14. Flint, H.J., Duncan, S.H., Scott, K.P., Louis, P., 2015. Links between diet, gut microbiota composition and gut metabolism. Proceedings of the nutrition society 74, 13-22. https://doi: $10.1017 / \mathrm{S} 0029665114001463$.

15. Franks, A.H., Harmsen, H.J., Raangs, G.C., Jansen, G.J., Schut, F., Welling, G.W., 1998. Variations of bacterial populations in human feces measured by fluorescent in situ hybridization with group-specific 16S rRNA-targeted oligonucleotide probes. Applied and environmental microbiology 64, 3336-3345. PMID: 9726880.

16. Fung, T.C., Olson, C.A., Hsiao, E.Y., 2017. Interactions between the microbiota, immune and nervous systems in health and disease. Nature neuroscience 20, 145. https://doi: $10.1038 / \mathrm{nn} .4476$.

17. Grimaldi, R., Cela, D., Swann, J.R., Vulevic, J., Gibson, G.R., Tzortzis, G., Costabile, A., 2017. In vitro fermentation of B-GOS: impact on faecal bacterial populations and metabolic activity in autistic and non-autistic children. FEMS microbiology ecology 93, fiw233. https://doi: 10.1093/femsec/fiw233.

18. Harmsen, H.J., Elfferich, P., Schut, F., Welling, G.W., 1999. A 16S rRNA-targeted probe for detection of lactobacilli and enterococci in faecal samples by fluorescent in situ hybridization. Microbial ecology in health and disease 11, 3-12. https://doi: 10.1080/089106099435862.

19. Harmsen, H.J., Wildeboer-Veloo, A.C., Grijpstra, J., Knol, J., Degener, J.E., Welling, G.W., 2000. Development of 16 S rRNA-Based Probes for theCoriobacterium Group and the Atopobium Cluster and Their Application for Enumeration of Coriobacteriaceaein Human Feces from Volunteers of Different Age Groups. Applied and environmental microbiology 66, 4523-4527. https://doi: 10.1128/AEM.66.10.4523-4527.2000. 
20. Hold, G.L., Schwiertz, A., Aminov, R.I., Blaut, M., Flint, H.J., 2003. Oligonucleotide probes that detect quantitatively significant groups of butyrate-producing bacteria in human feces. Applied and environmental microbiology 69, 4320-4324. https://doi: 10.1128/AEM.69.7.4320-4324.2003.

21. Huda-Faujan, N., Abdulamir, A., Fatimah, A., Anas, O.M., Shuhaimi, M., Yazid, A., Loong, Y., 2010. The impact of the level of the intestinal short chain fatty acids in inflammatory bowel disease patients versus healthy subjects. The open biochemistry journal 4, 53-58. https://doi: 10.2174/1874091X01004010053.

22. Hur, S.J., Lim, B.O., Decker, E.A., McClements, D.J., 2011. In vitro human digestion models for food applications. Food chemistry 125, 1-12. https://doi: 10.1016/j.foodchem.2010.08.036.

23. Kim, B., Hong, V.M., Yang, J., Hyun, H., Im, J.J., Hwang, J., Yoon, S., Kim, J.E., 2016. A review of fermented foods with beneficial effects on brain and cognitive function. Preventive nutrition and food science 21, 297-309. https://doi: 10.3746/pnf.2016.21.4.297.

24. Kouřimská, L., Adámková, A., 2016. Nutritional and sensory quality of edible insects. NFS Journal 4, 22-26. https://doi: 10.1016/j.nfs.2016.07.001.

25. Langendijk, P.S., Schut, F., Jansen, G.J., Raangs, G.C., Kamphuis, G.R., Wilkinson, M., Welling, G.W., 1995. Quantitative fluorescence in situ hybridization of Bifidobacterium spp. with genus-specific $16 \mathrm{~S}$ rRNA-targeted probes and its application in fecal samples. Applied and environmental microbiology 61, 3069-3075. PMID: 7487040.

26. Lee, S.-J., Lee, S.Y., Chung, M.-S., Hur, S.J., 2016. Development of novel in vitro human digestion systems for screening the bioavailability and digestibility of foods. Journal of functional foods 22, 113-121. https://doi: 10.1016/j.jff.2016.01.005.

27. Leschelle, X., Robert, V., Delpal, S., Mouille, B., Mayeur, C., Martel, P., Blachier, F., 2002. Isolation of pig colonic crypts for cytotoxic assay of luminal compounds: effects of hydrogen sulfide, ammonia, and deoxycholic acid. Cell biology and toxicology 18, 193 203. https://doi: 10.1023/A:1015515821390.

28. Levine, J., Ellis, C.J., Furne, J.K., Springfield, J., Levitt, M.D., 1998. Fecal hydrogen sulfide production in ulcerative colitis. The American journal of gastroenterology 93, 83-87. https://doi: 10.1111/j.1572-0241.1998.083_c.x.

29. Lopetuso, L.R., Scaldaferri, F., Petito, V., Gasbarrini, A., 2013. Commensal Clostridia: leading players in the maintenance of gut homeostasis. Gut pathogens 5, 23. https:// doi: 10.1186/1757-4749-5-23. 
30. Louis, P., Flint, H.J., 2017. Formation of propionate and butyrate by the human colonic microbiota. Environmental microbiology 19, 29-41. https://doi: 10.1111/1462-2920.13589.

31. Louis, P., Hold, G.L., Flint, H.J., 2014. The gut microbiota, bacterial metabolites and colorectal cancer. Nature reviews microbiology 12, 661. https://doi: 10.1038/nrmicro3344.

32. Manz, W., Amann, R., Ludwig, W., Vancanneyt, M., Schleifer, K.-H., 1996. Application of a suite of $16 \mathrm{~S}$ rRNA-specific oligonucleotide probes designed to investigate bacteria of the phylum cytophaga-flavobacter-bacteroides in the natural environment. Microbiology 142, 1097-1106. https://doi: 10.1099/13500872-142-5-1097.

33. Mayer, E.A., Tillisch, K., Gupta, A., 2015. Gut/brain axis and the microbiota. The Journal of clinical investigation 125, 926-938. https://doi: 10.1172/JCI76304.

34. Mills, D., Tuohy, K., Booth, J., Buck, M., Crabbe, M.J.C., Gibson, G., Ames, J., 2008. Dietary glycated protein modulates the colonic microbiota towards a more detrimental composition in ulcerative colitis patients and non- ulcerative colitis subjects. Journal of applied microbiology 105, 706-714. https://doi: 10.1111/j.1365-2672.2008.03783.x.

35. Mlcek, J., Rop, O., Borkovcova, M., Bednarova, M., 2014. A comprehensive look at the possibilities of edible insects as food in Europe-a review. Polish journal of food and nutrition sciences 64, 147-157. https://doi: 10.2478/v10222-012-0099-8.

36. Moon, J.S., Li, L., Bang, J., Han, N.S., 2016. Application of in vitro gut fermentation models to food components: A review. Food science and biotechnology 25, 1-7. https://doi:10.1 007/s10068-016-0091-X.

37. Pitcher, M., Beatty, E., Cummings, J., 2000. The contribution of sulphate reducing bacteria and 5-aminosalicylic acid to faecal sulphide in patients with ulcerative colitis. Gut 46, 6472. https//: doi: 10.1136/gut.46.1.64.

38. Powell, N., Walker, M.M., Talley, N.J., 2017. The mucosal immune system: master regulator of bidirectional gut-brain communications. Nature reviews gastroenterology \& hepatology 14, 143. https://doi: 10.1038/nrgastro.2016.191.

39. Premalatha, M., Abbasi, T., Abbasi, T., Abbasi, S., 2011. Energy-efficient food production to reduce global warming and ecodegradation: The use of edible insects. Renewable and sustainable energy reviews 15, 4357-4360. https://doi: 10.1016/j.rser.2011.07.115.

40. Rey, F.E., Gonzalez, M.D., Cheng, J., Wu, M., Ahern, P.P., Gordon, J.I., 2013. Metabolic niche of a prominent sulfate-reducing human gut bacterium. Proceedings of the national academy of sciences 110, 13582-13587. https://doi: 10.1073/pnas.1312524110. 
41. Ríos-Covián, D., Ruas-Madiedo, P., Margolles, A., Gueimonde, M., de los Reyes-Gavilán, C.G., Salazar, N., 2016. Intestinal short chain fatty acids and their link with diet and human health. Frontiers in microbiology 7, 185. https://doi: 10.3389/fmicb.2016.00185.

42. Rowland, I., Gibson, G., Heinken, A., Scott, K., Swann, J., Thiele, I., Tuohy, K., 2017. Gut microbiota functions: metabolism of nutrients and other food components. European journal of nutrition, 1-24. https://doi: 10.1007/s00394-017-1445-8.

43. Scott, K.P., Gratz, S.W., Sheridan, P.O., Flint, H.J., Duncan, S.H., 2013. The influence of diet on the gut microbiota. Pharmacological research 69, 52-60. https://doi: 10.1016/j.phrs.2012.10.020.

44. Scott, K.P., Jean-Michel, A., Midtvedt, T., van Hemert, S., 2015. Manipulating the gut microbiota to maintain health and treat disease. Microbial ecology in health and disease 26, 25877. https://doi: 10.3402/mehd.v26.25877.

45. Scott, K.P., Martin, J.C., Duncan, S.H., Flint, H.J., 2014. Prebiotic stimulation of human colonic butyrate-producing bacteria and bifidobacteria, in vitro. FEMS microbiology ecology 87, 30-40. https://doi: 10.1111/1574-6941.12186.

46. Stull, V.J., Finer, E., Bergmans, R.S., Febvre, H.P., Longhurst, C., Manter, D.K., Patz, J.A., Weir, T.L., 2018. Impact of edible cricket consumption on gut microbiota in healthy adults, a double-blind, randomized crossover trial. Scientific reports 8, 10762. https://doi.org/10.1038/s41598-018-29032-2.

47. Tan, J., McKenzie, C., Potamitis, M., Thorburn, A.N., Mackay, C.R., Macia, L., 2014. The role of short-chain fatty acids in health and disease, in: Alt, F. (Eds.), Advances in immunology. Academic Press, Amsterdam, pp. 91-119.

48. Thursby, E., Juge, N., 2017. Introduction to the human gut microbiota. Biochemical journal 474, 1823-1836. https://doi: 10.1042/BCJ20160510.

49. Tottey, W., Feria-Gervasio, D., Gaci, N., Laillet, B., Pujos, E., Martin, J.-F., Sebedio, J.-L., Sion, B., Jarrige, J.-F., Alric, M., 2017. Colonic transit time is a driven force of the gut microbiota composition and metabolism: in vitro evidence. Journal of neurogastroenterology and motility 23, 124-134. https://doi: 10.5056/jnm16042.

50. Tsujii, M., Kawano, S., Tsuji, S., Fusamoto, H., Kamada, T., Sato, N., 1992. Mechanism of gastric mucosal damage induced by ammonia. Gastroenterology 102, 1881-1888. PMID: 1587407.

51. Van den Abbeele, P., Grootaert, C., Marzorati, M., Possemiers, S., Verstraete, W., Gérard, P., Rabot, S., Bruneau, A., El Aidy, S., Derrien, M., 2010. Microbial community development in a dynamic gut model is reproducible, colon region specific, and selective 
for Bacteroidetes and Clostridium cluster IX. Applied and environmental microbiology 76, 5237-5246. https://doi: 10.1128/AEM.00759-10.

52. Van Huis, A., Van Itterbeeck, J., Klunder, H., Mertens, E., Halloran, A., Muir, G. and Vantomme, P. 2013. Edible insects: future prospects for food and feed security. FAO, Rome.

53. Verbeke, K.A., Boobis, A.R., Chiodini, A., Edwards, C.A., Franck, A., Kleerebezem, M., Nauta, A., Raes, J., Van Tol, E.A., Tuohy, K.M., 2015. Towards microbial fermentation metabolites as markers for health benefits of prebiotics. Nutrition research reviews $28,42-$ 66. https://doi: 10.1017/S0954422415000037.

54. Verhoeckx, K., Cotter, P., López-Expósito, I., Kleiveland, C., Lea, T., Mackie, A., Requena, T., Swiatecka, D., Wichers, H., 2015. The Impact of Food Bioactives on Health: in vitro and ex vivo models. Springer, Cham.

55. Vinke, P.C., El Aidy, S., van Dijk, G., 2017. The Role of Supplemental Complex Dietary Carbohydrates and Gut Microbiota in Promoting Cardiometabolic and Immunological Health in Obesity: Lessons from Healthy Non-Obese Individuals. Frontiers in nutrition 4, 34. https://doi: 10.3389/fnut.2017.00034.

56. Walker, A.W., Duncan, S.H., Leitch, E.C.M., Child, M.W., Flint, H.J., 2005. pH and peptide supply can radically alter bacterial populations and short-chain fatty acid ratios within microbial communities from the human colon. Applied and environmental microbiology 71, 3692-3700. https://doi: 10.1128/AEM.71.7.3692-3700.2005.

57. Wallace, J.L., Vong, L., McKnight, W., Dicay, M., Martin, G.R., 2009. Endogenous and exogenous hydrogen sulfide promotes resolution of colitis in rats. Gastroenterology 137, 569-578. https://doi: 10.1053/j.gastro.2009.04.012.

58. Wallner, G., Amann, R., Beisker, W., 1993. Optimizing fluorescent in situ hybridization with rRNA- targeted oligonucleotide probes for flow cytometric identification of microorganisms. Cytometry 14, 136-143. https://doi: 10.1002/cyto.990140205.

59. Zhao, X., Jiang, Z., Yang, F., Wang, Y., Gao, X., Wang, Y., Chai, X., Pan, G., Zhu, Y., 2016. Sensitive and simplified detection of antibiotic influence on the dynamic and versatile changes of fecal short-chain fatty acids. PloS one 11, e0167032. https://doi: 10.1371/journal.pone.0167032. 
List of tables:

607 Table 1 - Nutritional composition of TMIF (per 100g), as provided by the manufacturer.

608

609

610

611

612

613

614

\begin{tabular}{|c|c|}
\hline Component & Concentration \\
\hline Total sugar & $<0.10 \mathrm{~g}$ \\
\hline Amino acids & $5.4 \mathrm{~g}$ \\
\hline Cholesterol & $0.002 \mathrm{mg}$ \\
\hline Fiber & $3.0 \mathrm{~g}$ \\
\hline Fat & $39.4 \mathrm{~g}(\mathrm{saturated}-8.6 \mathrm{~g})$ \\
\hline Carbohydrates & $<0.10 \mathrm{~g}$ \\
\hline Humidity & $7.5 \mathrm{~g}$ \\
\hline Protein & $44.6 \mathrm{~g}$ \\
\hline Sodium & $142 \mathrm{mg}$ \\
\hline Energetic value & $539 \mathrm{kcal} \Leftrightarrow 2242 \mathrm{~kJ}$ \\
\hline
\end{tabular}

615

616

617

618

619

620

621

622

623

624

625

626

627 
631 Table 2 - 16 rRNA oligonucleotide probes and hybridisation conditions used in the FISH analysis. *These probes were used together in equimolar concentration of $50 \mathrm{ng} / \mu \mathrm{L}$.

\begin{tabular}{|c|c|c|c|}
\hline $\begin{array}{l}\text { Probe } \\
\text { name }\end{array}$ & Specificity & Sequence $\left(5^{\prime}-3^{\prime}\right)$ & Reference \\
\hline $\begin{array}{c}\text { Non } \\
\text { Eub338 }\end{array}$ & --- & ACTCCTACGGGAGGCAGC & Wallner et al. (1993) \\
\hline $\begin{array}{c}\text { Eub338 I- } \\
\text { II-III* }\end{array}$ & $\begin{array}{c}\text { Members of the domain } \\
\text { Bacteria }\end{array}$ & $\begin{array}{l}\text { GCTGCCTCCCGTAGGAGT } \\
\text { GCAGCCACCCGTAGGTGT } \\
\text { GCTGCCACCCGTAGGTGT }\end{array}$ & Daims et al. (1999) \\
\hline Bif164 & Bifidobacterium spp. & CATCCGGCATTACCACCC & $\begin{array}{c}\text { Langendijk et al. } \\
\text { (1995) }\end{array}$ \\
\hline Lab158 & $\begin{array}{l}\text { Lactobacillus spp./ } \\
\text { Enterococcus spp. }\end{array}$ & GGTATTAGCAYCTGTTTCCA & Harmsen et al. (1999) \\
\hline Bac303 & $\begin{array}{c}\text { Most Bacteroidaceae and } \\
\text { Prevotellaceae, some } \\
\text { Porphyromonadaceae }\end{array}$ & CCAATGTGGGGGACCTT & Manz et al. (1996) \\
\hline Erec482 & $\begin{array}{l}\text { Most of the Clostridium } \\
\text { coccoides/ Eubacterium } \\
\text { rectale group (Clostridium } \\
\text { cluster XIVa and XIVb) }\end{array}$ & GCTTCTTAGTCARGTACCG & Franks et al. (1998) \\
\hline Chis150 & $\begin{array}{c}\text { Most of the Clostridium } \\
\text { histolyticum group } \\
\text { (Clostridium cluster I and II) }\end{array}$ & TTATGCGGTATTAATCTYCCTTT & Franks et al. (1998) \\
\hline Rrec584 & Roseburia subcluster & TCAGACTTGCCGYACCGC & Walker et al. (2005) \\
\hline Ato291 & Atopobium cluster & GGTCGGTCTCTCAACCC & Harmsen et al. (2000) \\
\hline Prop853 & Clostridium cluster IX & ATTGCGTTAACTCCGGCAC & Walker et al. (2005) \\
\hline Fprau655 & $\begin{array}{c}\text { Fecalibacterium prausnitzii } \\
\text { and related sequences }\end{array}$ & CGCCTACCTCTGCACTAC & $\begin{array}{c}\text { Devereux et al. } \\
\text { (1992) }\end{array}$ \\
\hline DSV687 & $\begin{array}{c}\text { Most Desulfovibrionales } \\
\text { (excluding Lawsonia) and } \\
\text { Desulfuromonales }\end{array}$ & TACGGATTTCACTCCT & Hold et al. (2003) \\
\hline
\end{tabular}


638 Figure captions:

639 Figure 1 - Bacterial populations ( $\log ($ cells $/ \mathrm{mL})$, means \pm SD) detected by FISH-FCM in Fecal 640 samples (negative control ( $\square$ ), positive control ( $\square$ ), undigested TMIF ( $⿴$ ) and digested 641 TMIF ( : )). The used probes: I) total bacteria (Eub338), II) Bifidobacterium spp. (Bif164), 642 III) Lactobacillus spp. (Lab158), IV) most Bacteroidaceae and Prevotellaceae (Bac303) and 643 V) Atopobium cluster (Ato291), VI) Clostridium coccoides / Eubacterium rectale group 644 (Erec482), VII) most of the Clostridium histolyticum group (Chis150), VIII) Roseburia 645 subcluster (Rrec584), IX) Clostridium cluster IX (Prop853), X) Faecalibacterium prausnitzii 646 (Fprau655) and XI) Desulfovibrionales and Desulfuromonales (DSV687). Different letters 647 mark statistically significant $(\mathrm{p}<0.05)$ differences between samples at each sampling point.

Figure 2 - Concentration $(\mathrm{mM}$, means $\pm \mathrm{SD})$ of the SCFA and lactate produced along 650 fermentation time in Fecal samples (negative control ( $\square$ ), positive control ( $\square$ ), undigested 651

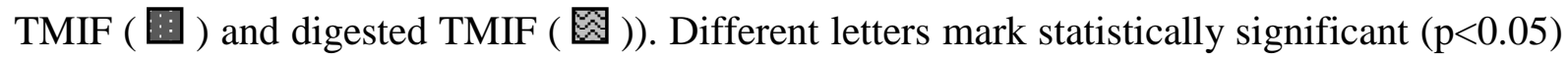
differences between samples at each sampling point.

653

654 Figure 3 - Concentration $(\mathrm{mM}$, means $\pm \mathrm{SD})$ of BCFA and valerate produced along 655 fermentation time in Fecal samples (negative control $(\square)$, positive control $(\square)$ ), undigested 656 TMIF ( 0 ) and digested TMIF ( 圈 )). Different letters mark statistically significant ( $<<0.05$ ) differences between samples at each sampling point.

658

Figure 4 - Concentration ( $\mathrm{mM}$, means $\pm \mathrm{SD}$ ) of ammonia produced along fermentation time in 660 Fecal samples (negative control ( $\square$ ), positive control ( $\square$ ), undigested TMIF ( $⿴$ ) and digested TMIF ( $⿴ 囗 ⿱ 一 一))$. Different letters mark statistically significant $(\mathrm{p}<0.05)$ differences between samples at each sampling point. 
